\title{
Joaquim Monteiro Caminhoá: um médico ilustrado do Império do Brasil, 1858-1896
}

\author{
Joaquim Monteiro Caminhoá: an exemplary doctor \\ of the Brazilian Imperial period, 1858-1896
}

\author{
Alex Gonçalves Varela \\ Professor, Departamento de \\ História/Universidade do Estado do \\ Rio de Janeiro. \\ Rio de Janeiro - RJ - Brasil \\ orcid.org/0000-0002-6853-0062 \\ alexvarelarj@terra.com.br
}

Recebido em 4 dez. 2017. Aprovado em 25 fev. 2018.
VARELA, Alex Gonçalves. Joaquim Monteiro Caminhoá: um médico ilustrado do Império do Brasil, 1858-1896. História, Ciências, Saúde Manguinhos, Rio de Janeiro, v.26, n.1, jan.-mar. 2019, p.335-345.

Resumo

O personagem Joaquim Monteiro Caminhoá foi um dos mais importantes homens de ciência que atuaram no Império do Brasil, tendo inclusive uma carreira consolidada e reconhecida internacionalmente. Sua trajetória histórica, contudo, ainda não foi devidamente estudada, existindo lacunas que estimulam reflexões. Este artigo resulta de uma pesquisa cujo objetivo é examinar as produções científicas elaboradas pelo estudioso e analisálas com a atenção voltada para o contexto social mais amplo em que foram concebidas. As suas produções são testemunhos importantes de comprovação da existência de produção científica no Império do Brasil na segunda metade do século XIX e revelam a riqueza do pensamento ilustrado brasileiro.

Palavras-chaves: Joaquim Monteiro Caminhoá (1836-1896); história das ciências; Brasil Império; botânica; Faculdade de Medicina do Rio de Janeiro.

\begin{abstract}
Joaquim Monteiro Caminhoá was one of the most important men of science during the Brazilian Imperial period, with an established career and international recognition. But his historical trajectory has not been properly studied, and it features gaps which can lead to reflections. This article is the result of research examining the scientific production compiled by this scholar and analyzing it with attention to the broader social context in which it was conceived. Caminhoa's production is important proof that scientific production was present in the Brazilian Imperial period during the second half of the nineteenth century, and reveals the richness of thought of this Brazilian scholar.
\end{abstract}

Keywords: Joaquim Monteiro Caminhoá (1836-1896); history of science; Brazilian Imperial period; botany; Faculdade de Medicina do Rio de Janeiro. 
$\mathrm{O}_{\mathrm{m}}^{\circ}$ objetivo da pesquisa que dá origem a este artigo é o estudo da trajetória de vida do médico e botânico Joaquim Monteiro Caminhoá, por meio dos seus textos científicos, e a sua relação com o processo de emergência e consolidação das ciências naturais no Império do Brasil. O trabalho a ser desenvolvido insere-se no campo da história das ciências ilustrada (séculos XVIII-XIX).

Joaquim Monteiro Caminhoá nasceu em 21 de dezembro de 1836, na cidade de Salvador, província da Bahia. Era filho de Luiza Monteiro Caminhoá e Manuel José Caminhoá, seu irmão chamava-se Luiz Monteiro Caminhoá. Tornou-se doutor em medicina pela Faculdade de Medicina da Bahia (1858). Em 1861, entrou para a Faculdade de medicina do Rio de Janeiro como opositor de ciências acessórias, sendo depois nomeado lente de botânica e zoologia (1871), com a tese Das plantas tóxicas do Brasil. Foi também nomeado lente de história natural do Colégio Pedro II.

Joaquim Monteiro Caminhoá integrou como sócio a Academia Imperial de Medicina, foi um dos fundadores da Associação Brasileira de Aclimação, foi patrono da cadeira 57, destinada à cirurgia naval, da Academia Brasileira de Medicina Militar, e membro de associações científicas estrangeiras, como a Sociedade de Botânica da França e a Sociedade de Ciências Naturais de Edimburgo. Caminhoá faleceu em 28 de novembro de 1896, no Rio de Janeiro.

O objetivo principal deste estudo é recuperar a trajetória de vida do médico Joaquim Monteiro Caminhoá e a sua contribuição para a institucionalização das ciências naturais no Império do Brasil. Seus textos científicos são valiosos e constituem-se como fontes importantes para a história da medicina no âmbito do Império do Brasil. Sua produção inclui dicionários, artigos publicados em periódicos científicos, memórias, teses de concurso, relatórios/planos técnicos, discursos, extratos de lições, livros e compêndios, entre outros. Portanto, uma profunda pesquisa sobre a atividade científica do médico torna-se necessária para preencher a lacuna deixada pela historiografia.

A pesquisa sobre a trajetória de Joaquim Monteiro Caminhoá foi iniciada com o levantamento da bibliografia já existente sobre a trajetória do personagem. Em outras palavras, procuramos localizar o conjunto de textos, aí incluindo verbetes, artigos, livros, discursos, dentre outros, produzidos sobre o botânico.

A primeira obra redigida sobre Caminhoá que localizamos foi o verbete elaborado pelo médico e escritor Sacramento Blake (1898) para o Dicionário bibliográfico brasileiro, obra produzida no final do século XIX. O dicionário de Augusto Victorino Alves Sacramento Blake é considerado por muitos autores e críticos especializados a mais completa bibliografia de autores brasileiros do período colonial até o século XIX. A obra apresenta a biografia de cada autor e faz uma compilação das obras por eles produzidas. E é no quarto volume dessa obra, publicado em 1898, que Sacramento Blake se debruça sobre a vida de Joaquim Monteiro Caminhoá. O verbete de Blake se propõe a fazer uma análise biográfica de Caminhoá, chamando atenção para aspectos da vida do personagem, como: nascimento e morte, filiação, formação, serviços prestados, títulos, medalhas recebidas, sociedades médicas às quais pertenceu, além de uma enumeração de sua produção.

Já no século XX, no ano de 1932, Fernando Magalhães, médico, professor, orador e exocupante da cadeira 33 da Academia Brasileira de Letras, escreveu o livro do Centenário da 
Faculdade de Medicina do Rio de Janeiro. Nessa obra comemorativa, o autor redigiu uma curta biografia sobre Joaquim Monteiro Caminhoá, que fora um dos mais notáveis pesquisadores das áreas de botânica, biologia e zoologia no século XIX. O texto de Fernando Magalhães segue o mesmo padrão do conjunto de dados biográficos apresentado por Blake, e apresenta, como este último, uma lista das publicações de Caminhoá.

Por sua vez, na década de 1960, o médico Carlos da Silva Araújo, patrono da cadeira 95 da Academia Nacional de Medicina, redigiu um artigo sobre Caminhoá. No estudo apresentado, Araújo (s.d.) apresentou a trajetória de vida do personagem, enfatizando a atuação como professor da Faculdade de Medicina do Rio de Janeiro, a admissão como sócio na Academia Imperial de Medicina e alguns de seus trabalhos realizados na mesma instituição, além de atividades que desempenhou como botânico, comentou sobre a mais importante obra produzida por Caminhoá, Elementos de botânica geral e médica, a nomeação para a cátedra de história natural do Colégio Pedro II e mencionou títulos, comendas e homenagens póstumas recebidas pelo estudioso. Portanto, esse estudo se diferiu dos demais até então apresentados pelo fato de Araújo ter escolhido alguns temas na trajetória do letrado e não ter apresentado uma biografia de forma linear, com uma narrativa que privilegiasse datas e fatos da vida do homem de ciência do Império.

No início da década de 1970, o médico e professor Carlos da Silva Lacaz (1971) publicou uma curta biografia sobre Caminhoá no livro Vultos da medicina brasileira. Lacaz apresentou o mesmo tipo de informações biográficas sobre Caminhoá expostas por Blake e Fernando Magalhães, conforme acima comentamos. Listou apenas alguns trabalhos acadêmicos de Caminhoá. Um dos diferenciais do texto de Lacaz foi a anexação de uma matéria do Jornal do Commércio, que, em alusão à morte de Joaquim Monteiro Caminhoá, escreve que o autor fora um dos mais notáveis botânicos brasileiros, cujas obras serviriam de referência para as gerações posteriores de estudantes, especialmente por conta da precisão e minúcia, além da escrita atraente. O jornal considera que os escritos de Caminhoá marcam seu lugar como dos mais eficientes estudos das ciências naturais.

Outro autor analisado foi Orsini Carneiro Giffonni, médico e dedicado ao magistério, foi professor de antropologia da Faculdade de Filosofia, Ciências e Letras de Catanduva, interior de São Paulo, bem como de biologia do Instituto de Educação Padre Anchieta. Sua principal obra foi o Dicionário biobibliográfico brasileiro de escritores médicos - 1500-1899 (Giffoni, 1972). Na obra, o autor se dedica a apresentar uma biografia daqueles que eram considerados os mais importantes médicos escritores do período por ele escolhido (15001899). Apesar das muitas críticas, por deixar de fora do seu dicionário muitos importantes médicos escritores, o autor não deixou de citar Joaquim Monteiro Caminhoá. Giffoni apresenta uma curta biografia que salienta, especialmente, as publicações de Caminhoá.

Outro autor analisado foi Santos Filho (1991), médico e professor universitário, além de autor da obra História geral da medicina brasileira, composta por dois volumes, cuja primeira edição é de 1977. Essa publicação era a ampliação e reforma da obra História da medicina no Brasil do século XVI ao século XIX, que fora publicada em 1947.

Lycurgo dos Santos Filho, juntamente com Carlos da Silva Lacaz, insere-se numa tradição de pesquisa de médicos que se interessaram pela história da medicina brasileira e passaram a realizar pesquisas na área e a publicar livros e artigos. Registra-se que a história da medicina 
que a maioria desses médicos apresenta em suas obras tem um caráter memorialístico, preocupada especialmente em se referir aos grandes vultos da área no Brasil e mencionar seus feitos. Porém, é importante destacar que muitas dessas obras igualmente informam sobre fontes para subsidiar futuras pesquisas. No volume dois da supracitada obra cujo conteúdo é centrado na história da medicina do Império, Lycurgo, na parte referente à botânica e zoologia médicas, mencionou Joaquim Monteiro Caminhoá, apresentando um curto trecho sobre o personagem em que mencionava dados sobre sua formação, atuação e citação de alguns de seus títulos publicados.

Portanto, todos os trabalhos já mencionados produzidos sobre Caminhoá são de autoria de médicos que redigiram curtas biografias, apresentadas de forma linear, privilegiando uma narrativa de datas e fatos, com exceção de Carlos da Silva Araújo, que selecionou alguns temas da trajetória do estudioso. Contudo, toda a produção mencionada não se caracteriza por ser de estudos de análise crítica profunda, pois não contextualizam a produção científica do médico do Império do Brasil. Eles limitaram-se a elencar uma lista das suas obras, sem apresentar uma reflexão crítica delas.

O primeiro estudo que localizamos realizado por um historiador sobre a trajetória de vida de Caminhoá foi de Fonseca (2000). Historiadora das ciências, pesquisadora do Departamento de Pesquisa da Casa de Oswaldo Cruz, professora do Programa de Pós-graduação em História das Ciências e da Saúde, Maria Rachel Fróes da Fonseca é coordenadora do Dicionário histórico biográfico das ciências da saúde no Brasil - 1832-1930, publicado em versão on-line no início do século XXI.

A autora apresenta uma biografia mais detalhada da vida de Caminhoá, com informações mais precisas e detalhadas sobre dados pessoais, trajetória profissional e produção intelectual. Neste último item, apresentou uma relação minuciosa de suas conferências, cursos, artigos, pareceres, teses, relatórios, entre outros. Por exemplo, Fonseca (2000) destacou, dentre outras coisas, os dez cursos de botânica popular proferidos por Caminhoá nas Conferências Populares da Glória, que eram realizadas na cidade do Rio de Janeiro desde 1973.

Inserido também no mesmo espaço institucional da pesquisadora supracitada, o historiador Jaime Benchimol (1999), em Dos micróbios aos mosquitos: febre amarela e a revolução pasteuriana no Brasil, analisou a trajetória de Domingos José Freire e João Batista de Lacerda, dois personagens que enfrentaram de forma teórica e prática a febre amarela e outros flagelos que grassavam nos núcleos urbanos do sudeste do país durante o Império. E um dos homens que atuaram com Domingos José Freire foi Joaquim Monteiro Caminhoá, que integrou a Comissão de Estudos Sobre Febre Amarela (1883 a 1885), dirigidos por Freire, e, depois, foi também seu auxiliar na continuação dos referidos estudos. Benchimol (1999) também argumenta que Caminhoá foi o principal porta-voz de Domingos Freire na Academia Imperial de Medicina. O historiador utilizou diversas obras de Caminhoá como fonte de análise.

Prosseguindo, o primeiro trabalho acadêmico de pós-graduação que localizamos foi a dissertação de mestrado de Wandir Vieira Leal Santos, defendida no Programa de História da Ciência da Pontifícia Universidade Católica de São Paulo. Nesse estudo, Santos (2017) analisou a principal obra de Caminhoá, Elementos de botânica geral e médica, publicada no ano de 1877, enfatizando a análise do conceito de espécie. O trabalho de Wandir possui 
relevância, entre outras coisas, por analisar as obras do médico-botânico do Império brasileiro dentro do contexto sociocientífico de sua produção, observando com quais autores Caminhoá dialogava e quais ele refutava para a construção do conceito de "espécie".

A historiadora das ciências Begonha Bediaga também analisou textos de Caminhoá em seu estudo sobre o Imperial Instituto Fluminense de Agricultura (IIFA) no período de 1860 a 1891. Bediaga (2014) analisou o Relatório acerca dos jardins botânicos, de 1874, produzido por Caminhoá, destacando as críticas que ele realizou ao Jardim Botânico da Corte, administrado na época pelo IIFA.

Joaquim Monteiro Caminhoá foi um dos mais importantes homens de ciência no Brasil imperial, tendo inclusive uma carreira consolidada e reconhecida internacionalmente. Atuou em instituições científicas do Império e em diversas sociedades científicas, além de ter publicado livros e artigos. O estudioso se dedicou a produzir conhecimento científico sobre questões médicas e botânicas. Contudo, sua trajetória acadêmica ainda não foi devidamente estudada, e suas produções científicas ainda não foram analisadas em profundidade. Dessa forma, há lacunas que precisam ser preenchidas pelos estudiosos e caminhos amplos e profícuos que merecem ser explorados e estimulam novas reflexões.

O trabalho de pesquisa insere-se no campo da história das ciências. Registremos que partilhamos com Vessuri (1986) o entendimento da "ciência como cultura". A autora argumentou sobre a necessidade de romper com as concepções que compreendem a ciência como conhecimento universal a respeito dos fenômenos naturais, os quais, por serem os mesmos em toda parte, tornavam irrelevante considerar os contextos sociais, culturais e políticos das práticas científicas: "Se se entende a ciência como uma cultura sustentada por uma tradição existente, pode-se colocar uma quantidade de problemas interessantes acerca de suas características em diferentes sociedades" (Vessuri, 1986, p.9). Entre esses problemas, a autora registrou a necessidade "inelutável de deseuropeização da imagem do conhecimento científico", adotando assim um "enfoque universalista mais amplo, e mais sábio" (p.13).

Os trabalhos em história das ciências têm apontado a necessidade de compreender a forma como se deu a contextualização de determinada cultura científica num espaço-tempo definido, uma vez que, quando esta é considerada fora de seus mais diversos e interligados contextos, torna-se uma ficção (Polanco, 1986, p.42). É necessário tentar compreender a dinâmica própria de cada uma das sociedades em questão. O processo de desenvolvimento das ciências está inserido no processo histórico geral, no qual atuam fatores econômicos, sociais, políticos e culturais, não se restringindo apenas ao processo de produção de conhecimento. Uma gama intensa de estudos vem sendo realizada desde a década de 1980 com o intuito de conhecer a história da ciência nos países latino-americanos, em especial no Brasil, e o desenvolvimento das práticas científicas nesse espaço.

O interesse pela análise das produções científicas produzidas pelo estudioso justificase pelo fato de serem importantes materiais de produção do conhecimento, deixando transparecer a sua contribuição para o processo de emergência e consolidação das ciências naturais no Império do Brasil na segunda metade do século XIX. Por meio da análise das suas obras, entre outras questões, é possível observar a concepção de ciência com que Caminhoá trabalhava e sua postura téorico-metodológica. Além disso, seus textos permitem 
identificar as apropriações que fazia das modernas teorias científicas médico-botânicas e como buscava aplicá-las em seu contexto local, os autores com quem dialogava bem como os autores que refutava. Sua produção científica é, portanto, uma peça importante para a compreensão da forma como se deu o processo de institucionalização das ciências naturais no Império do Brasil.

Os textos científicos produzidos por Caminhoá serão analisados sem perder de vista o contexto social mais amplo em que foram concebidos, como tem sido proposto pela nova historiografia das ciências. Ao fazer, então, uma leitura contextualizada dos textos, é possível perceber as questões formuladas pelo estudioso, os argumentos por ele apresentados e em que medida aceitava as ideias então predominantes no debate científico da época sobretudo no campo das ciências naturais - e delas se apropriava, ou as contestava, repelia, e, às vezes, até as ignorava. Permite observar também quais foram os autores lidos e as obras analisadas pelo estudioso. Portanto, seus textos científicos serão analisados a partir do contexto no qual ele escrevia, uma vez que são "construídos segundo regras variáveis no tempo e no espaço social, um objeto que seria ingênuo considerar transparente em si mesmo, como se relatasse fatos brutos" (Pestre, 1996, p.37).

Ainda tecendo considerações sobre a necessidade de contextualização dos textos, as reflexões de Figueirôa (2001) quanto à construção de biografias serão importantes contribuições para o nosso estudo, ainda que nosso objetivo não seja a elaboração de uma biografia, por permitirem refletir sobre a vida científica do personagem que será estudado. Essa autora considerou de fundamental importância para a construção da biografia de um personagem a reconstrução do contexto histórico de sua produção e a legitimação e veiculação do conhecimento científico por ele elaborado. Não uma narrativa biográfica que busca associar o personagem em uma cronologia ordenada, dando-lhe uma personalidade coerente estável, realizando ações em inércia e tomando decisões sem incertezas, muito menos uma perspectiva que busca transformar o indivíduo num gênio ou num mito. Assim, iremos privilegiar alguns aspectos da trajetória de vida do autor, sobretudo aqueles relativos à sua prática científica e ao processo de construção do conhecimento científico, dentro do contexto histórico no qual estavam situados.

Dentre os temas a serem trabalhados estão a relação ciência e público; ciência e trajetória; ciência e produção do conhecimento; ciência e sociabilidades; ciência e Ilustração; ciência e Império; ciência e viagens, dentre outros que possam surgir a partir da leitura das produções científicas de Caminhoá.

Os historiadores das ciências cada vez mais estão ampliando o seu interesse em estudar a trajetória de vida dos homens de ciência do Império do Brasil. Os médicos e estudiosos de história natural têm recebido um tratamento considerável por parte da historiografia.

A dissertação de Morais (2005) sobre o médico e botânico Francisco Freire Alemão (17971874) se insere nessa linha de pesquisa. A historiadora teve como objetivo central reconstruir os caminhos do personagem, um dos expoentes da ciência oitocentista brasileira. E, para tal, buscou recompor o contexto científico em que o personagem atuou. O nosso trabalho de pesquisa tomará como base o trabalho da referida autora.

Ferreira (1994) também tem um valioso artigo sobre trajetórias acadêmicas e profissionais de homens de ciências no Império do Brasil. O historiador das ciências analisou a 
trajetória de João Vicente Torres Homem, um dos mais destacados clínicos do século XIX, apresentando uma excelente descrição da sua carreira médica.

Por sua vez, Benchimol (1999) estudou a trajetória de dois bacteriologistas: Domingos José Freire e João Batista de Lacerda. O autor procurou mostrar a contribuição dos dois médicos para a institucionalização das ciências biomédicas em nosso país em finais do século XIX.

Sá (2001) pesquisou sobre a trajetória do naturalista brasileiro João Barbosa Rodrigues, enfatizando seus estudos botânicos no cenário nacional e internacional, buscando compreender a especificidade da trajetória do personagem de amador a cientista e o apoio recebido do barão de Capanema.

Assim, tomaremos as referidas obras de Morais, Ferreira, Benchimol e Sá como base para o nosso projeto de pesquisa, com a possibilidade de acrescentar outros à medida que a pesquisa avance, pois buscam reconstruir as trajetórias dos homens de ciências estudados a partir do contexto social em que atuam.

Para reconstituir a formação e atuação de Joaquim Monteiro Caminhoá como médicobotânico no Brasil, em quais instituições foi admitido e em quais sociedades científicas atuou, contaremos com os verbetes do Dicionário Histórico-Biográfico das Ciências da Saúde no Brasil (1832-1930) (Fonseca, 2000). Edmundo (1956) será útil para a reconstituição de um breve perfil da medicina colonial e da medicina na época da fundação das escolas anatômica, cirúrgica e médica do Rio de Janeiro e da Bahia, e também no momento posterior à sua criação, baseamo-nos no estudo conjunto de Ferreira, Fonseca e Edler (2001). O estudo de Pimenta (2003) adicionará mais dados a respeito do exercício da medicina sob a regulamentação da fisicatura. Coelho (2000) e Edler (2011) serão a pedra de toque, ao analisar os parâmetros e critérios necessários para que um médico conseguisse prestígio e reconhecimento, tanto entre sua clientela como entre seus pares. O trabalho de Kury (1992) sobre a Academia Imperial de Medicina será de extrema valia, uma vez que Caminhoá integrou os quadros dela, e o de Lopes (1997) também de considerável valor, uma vez que Caminhoá foi membro atuante da Sociedade Velosiana das Ciências Naturais.

Estudaremos a botânica médica, antiga disciplina presente em reformas curriculares das instituições de ensino médico do país no século XIX. Joaquim Monteiro Caminhoá foi, como já informamos, lente de botânica e zoologia da Faculdade de Medicina do Rio de Janeiro e professor da cadeira de história natural do Imperial Colégio Pedro II. Buscaremos realizar um breve histórico de como esse ramo da botânica se construiu ao longo dos séculos e o porquê de sua utilização para a formação de cirurgiões e médicos. Para a reconstrução dessa área do conhecimento utilizaremos a obra de Mayr (1998), bem como de outros autores como Le Goff (1991) e Sournia (1997).

Consideramos Joaquim Monteiro Caminhoá na perspectiva de um homem da ilustração oitocentista. As "luzes" chegaram por aqui durante o reformismo ilustrado pombalino e mariano, na segunda metade do século XVIII, trazendo consigo uma série de situações de inovação. Os naturalistas partilhavam da profunda crença no poder da ciência, e suas práticas científicas caracterizavam-se pelo utilitarismo e pelo pragmatismo, características da história natural moderna (Kury, 2001). E, conforme argumentou Dias (jan.-mar. 1968, p.162), tais características se fizeram presentes também na geração dos homens de ciência do 
século XIX, inclusive Joaquim Monteiro Caminhoá. A valorização da ciência como elemento importante para a transformação da sociedade e a inclinação pragmática e utilitarista do seu trabalho deixam transparecer a atualização do seu pensamento científico.

O recorte cronológico do projeto de pesquisa está circunscrito ao período que vai de 1859, ano em que Caminhoá concluiu o doutorado em medicina pela Faculdade de Medicina da Bahia, até 1896, ano de sua morte. Por sua vez, o recorte espacial é a cidade do Rio de Janeiro, capital do Império e espaço onde o personagem atuou profissionalmente.

Reconstruir a trajetória de Joaquim Monteiro Caminhoá no âmbito do contexto científico do Império do Brasil é o objetivo central da pesquisa. Por sua vez, a premissa fundamental de análise consiste em verificar a sua contribuição para o processo de emergência e consolidação das ciências naturais no Brasil Império da segunda metade do século XIX. Tal contribuição será investigada por meio da sua produção científica, que é constituída por livros, artigos, discursos, pareceres, compêndios, entre outros. Sua participação em congressos e seminários no Brasil e no exterior e sua inserção em academias e sociedades científicas também são elementos importantes para comprovar a sua contribuição para o referido processo. A participação em viagens e comissões científicas constituem relevantes formas de avaliar sua atuação. Buscaremos, portanto, comprovar o quanto o personagem foi ativo para a institucionalização das ciências em nosso país.

Dentre os artigos redigidos por Caminhoá, cuja análise já foi iniciada, encontra-se "Utilidade das ciências naturais", publicado no Barão de Macaúbas: Periódico Científico, Literário e Noticioso, na Bahia, em 9 de setembro de 1888. No estudo, o autor argumenta sobre a utilidade do estudo das ciências naturais, considerando que aqueles que as desconhecem "andam errantes em seu próprio país" (Caminhoá, 9 set. 1888, p.2). E, a seguir, em tom bastante lamentoso, afirmou que "triste papel representam os homens de estado que desconhecem as riquezas naturais de seu país, graças às quais podem prosperar a agricultura e as indústrias que se alimentam com as matérias fornecidas pelos seres da natureza!" (p.2).

Prosseguiu argumentando sobre a importância dos animais e vegetais para a vida do homem, e afirmou que era um "crime" em nosso país não se estudar as ciências naturais, uma vez que por aqui as "essências florestais estão por milhares" (Caminhoá, 9 set. 1888, p.2). Um mineral, uma planta, um inseto, um verme, segundo Caminhoá, são assuntos que nos revelam as leis da natureza, esse mundo a ser decifrado pelo homem. Aquele que estuda o mundo natural é capaz de abrir para os seus semelhantes "o vasto cofre que guarda os imensos tesouros por Deus tão generosamente concedidos, tesouros que são eternos, que dão lucros incalculáveis a quem os sabe procurar..." (p.2). Em outras palavras, para Caminhoá, a natureza é uma fonte de conhecimentos e de riquezas.

Na parte final do texto, Caminhoá (9 set. 1888, p.2) definiu o que significa estudar a natureza:

É procurar aproximar-se do Fator dos mundos, porque é procurar decifrar as leis imutáveis e eternas que ele escreveu no seio da terra, nas entranhas dos animais, nas pétalas das flores, na atmosfera, e nas águas onde pululam os infinitamente pequenos, de cuja existência, ignorada até bem pouco, depende a saúde, e às vezes a vida dos inúmeros seres que cobrem a superfície da terra e as profundezas do oceano. 
Na fase atual da pesquisa, iniciamos a tentativa de localizar o conjunto da produção científica de Joaquim Monteiro Caminhoá. Após a realização de um levantamento bibliográfico nas principais instituições arquivísticas e bibliotecas, como Fundação Biblioteca Nacional do Rio de Janeiro (FBNRJ), Instituto Histórico e Geográfico Brasileiro (IHGB), Museu Nacional do Rio de Janeiro/UFRJ (MN/UFRJ), Biblioteca do Jardim Botânico do Rio de Janeiro (BJB), Arquivo Nacional (AN), Real Gabinete Português de Leitura (RGPL), entre outras, já localizamos a maior parte das obras do estudioso, sobretudo as do campo da botânica, aquelas de maior interesse para o projeto. Dentre tais obras, vale mencionar: Botânica geral e médica. Rio de Janeiro: Tipografia Nacional, 1879-1884 (Loc.: UFRJ/CT-OR Obras Raras 581 C183); Curso de botânica popular. Rio de Janeiro: J. Villeneuve, 1876 (Loc.: FBNRJ Obras Gerais V - 166, 4, 19 - n.1); Das plantas tóxicas do Brasil. Rio de Janeiro: Perspectiva, 1871 (Tese - Faculdade de Medicina do Rio de Janeiro) [Loc.: MN Obras Raras 581.69 C183]; Família das euforbiáceas. Rio de Janeiro: Imprensa Industrial, 1879 (Tese para o concurso de história natural do Colégio de D. Pedro II) [Loc.: IHGB 137.5.16 n.5]; e Relatório acerca dos jardins botânicos. Rio de Janeiro: Tipografia Nacional, 1874 (Loc.: FBNRJ Obras Gerais II - 155, 7, 4 n.4). Tais títulos no campo da botânica serão lidos levando em consideração o contexto social em que foram produzidas, conforme já informado em parágrafos anteriores.

No levantamento das obras produzidas pelo autor, consideramos interessante a sua reflexão sobre um problema de saúde pública que voltou a atingir a população brasileira nos dias de hoje, a febre amarela. O autor produziu reflexões acerca dessa enfermidade. Localizamos as seguintes obras: A febre amarela e a cólera-morbus serão provimentos de um envenenamento miasmático? Bahia: C. Poggetti, 1858 (Loc.: FBNRJ Obras Gerais II - 322, 6, 7 n.28); Cadeira de patologia interna febre amarela - (proposições) Três sobre cada uma das cadeiras da faculdade. Rio de Janeiro: Faculdade de Medicina do Rio de Janeiro, 1886 (Loc.: UFRJ/CCS Teses T1886 CAMI v.255).

Ainda não foi possível localizar todo o conjunto de artigos, pareceres, discursos, entre outros, que são mencionados como sendo de sua autoria. Também não conseguimos localizar correspondências de Caminhoá com cientistas nacionais ou estrangeiros ou diários de viagens. Essa é uma etapa que ainda não foi finalizada. Há necessidade de vasculharmos com mais profundidade arquivos e bibliotecas para exaurirmos todo o levantamento das fontes. Por sua vez, a Biblioteca da Academia Nacional de Medicina (ANM) está com suas atividades paralisadas, fato que dificulta a pesquisa, uma vez que Caminhoá pertenceu à instituição na época do Império. E ainda não conseguimos acessar a documentação do Centro de Memória e Documentação do Colégio Pedro II (Nudom).

As considerações aqui apresentadas são os passos da pesquisa que consiste em analisar a trajetória de Joaquim Monteiro Caminhoá no cenário científico nacional, em especial da história natural, destacando a botânica por intermédio das fontes já citadas.

\section{REFERÊNCIAS}

ARAÚJO, Carlos da Silva.

Joaquim Monteiro Caminhoá. Patrono da Cadeira n.95. Datilografado. Academia Nacional de Medicina, Rio de Janeiro. s.d.
BEDIAGA, Begonha.

Marcado pela própria natureza: o Imperial

Instituto Fluminense de Agricultura, 1860 a 1891. Rio de Janeiro: FGV; Faperj. 2014. 
BENCHIMOL, Jaime Larry.

Dos micróbios aos mosquitos: febre amarela e a revolução pasteuriana no Brasil. Rio de Janeiro: Editora Fiocruz; Editora UFRJ. 1999.

BLAKE, Sacramento.

Dicionário bibliográfico brasileiro. v.4. Rio de Janeiro: Imprensa Nacional. 1898.

CAMINHOÁ, Joaquim Monteiro. Utilidade das ciências naturais. Barão de Macaúbas: Periódico Científico, Literário e Noticioso, ano 3, n.32, p.2. 9 set. 1888.

COELHO, Edmundo Campos.

As profissões imperiais: medicina, engenharia e advocacia no Rio de Janeiro, 1822-1930. Rio de Janeiro: Record. 2000.

DIAS, Maria Odila da Silva.

Aspectos da Ilustração no Brasil. Revista do Instituto Histórico e Geográfico Brasileiro, v.278, p.105-170. jan.-mar. 1968.

EDLER, Flavio Coelho.

Medicina no Brasil Imperial: clima, parasitas e patologia tropical. Rio de Janeiro: Fiocruz Editora. 2011.

EDMUNDO, Luiz.

O Rio de Janeiro no tempo dos vice-reis. v.2. Rio de Janeiro: Conquista. 1956.

FERREIRA, Luiz Otávio.

João Vicente Torres Homem: descrição da carreira médica no século XIX. Physis, Revista de Saúde Coletiva, v.4, n.1, p.57-78. 1994.

FERREIRA, Luiz Otávio; FONSECA, Maria Rachel Fróes da; EDLER, Flávio.

A Faculdade de Medicina do Rio de Janeiro no séc. XIX: a organização institucional e os modelos de ensino. In: Dantes, Maria Amélia M. (org.). Modelos institucionais científicos na história da ciência no Brasil: estudos e caso (1800-1950). Rio de Janeiro: Editora Fiocruz. p.59-80. 2001.

FIGUEIRÔA, Silvia F. de Mendonça. Para pensar as vidas de nossos cientistas tropicais. In: Heizer, Alda; Videira, Antonio Augusto Passos (Org.). Ciência, civilização e império nos trópicos. Rio de Janeiro: Access. 2001.

FONSECA, Maria Rachel Fróes da (Coord.). Dicionário histórico-biográfico das ciências da saúde no Brasil (1832-1930). Rio de Janeiro: Casa de Oswaldo Cruz/Fiocruz. Disponível em: $<$ http://www.dichistoriasaude.coc.fiocruz.br>. Acesso em: 17 set. 2017. 2000.

GIFFONI, Orsini Carneiro. Dicionário biobibliográfico brasileiro de escritos médicos (1500-1899). São Paulo: Nobel. 1972.
KURY, Lorelai.

Entre utopia e pragmatismo: a história natural no Iluminismo tardio. In: Soares, Luiz Carlos (Org.). Da revolução científica à big (business) science. São Paulo: Hucitec; Niterói: Eduff. 2001.

KURY, Lorelai.

O império dos miasmas: a Academia Imperial de Medicina. Dissertação (Mestrado) - Universidade Federal Fluminense, Niterói. 1992.

LE GOFF, Jacques (Org.).

As doenças têm história. Lisboa: Terramar. 1991.

LACAZ, Carlos da Silva.

Vultos da medicina brasileira. São Paulo:

Laboratório Pfizer do Brasil. 1971.

LOPES, Maria Margaret.

O Brasil descobre a pesquisa científica: as ciências naturais e os museus no Brasil no século XIX. São Paulo: Hucitec. 1997.

MAYR, Ernest.

O desenvolvimento do pensamento biológico: diversidade, evolução e herança. Brasília: Editora da UnB. 1998.

MAGALHÃES, Fernando.

Centenário da Faculdade de Medicina do Rio de Janeiro. Rio de Janeiro: Tipografia A. P. Barthel. 1932.

MORAIS, Rita de Cássia de Jesus.

Nos verdes campos da ciência: a trajetória acadêmica do médico e botânico Francisco Freire-Allemão (1797-1874). Dissertação (Mestrado em História das Ciências da Saúde) Casa de Oswaldo Cruz/Fiocruz, Rio de Janeiro. 2005.

PESTRE, Dominique.

Por uma nova história social e cultural das ciências: novas definições, novos objetos, novas abordagens. Cadernos IG/Unicamp, v.6, n.1, p.533. 1996 .

PIMENTA, Tânia Salgado.

Terapeutas populares e instituições médicas na primeira metade do século XIX. In: Chalhoub, Sidney et al. (Org.). Artes e ofícios de curar no Brasil: capítulos de história social. Campinas: Editora Unicamp. 2003.

POLANCO, Xavier.

La ciencia como ficción: historia y contexto. In: Saldaña, Juan José (Ed.). El perfil de la ciencia en America. Cuadernos de Quipu, v.1, p.52-87. 1986.

SÁ, Magali Romero.

O botânico e o mecenas: João Barbosa Rodrigues e a ciência no Brasil na segunda metade do século XIX. História, Ciências, Saúde Manguinhos, v.8, suplemento, p.899-924. 2001. 
SANTOS, Wandir Vieira Leal.

A concepção de espécie na visão do botânico brasileiro Joaquim Monteiro Caminhoá. Dissertação (Mestrado) - Pontifícia Universidade Católica de São Paulo, São Paulo. 2017.

SANTOS FILHO, Lycurgo de Castro.

História geral da medicina brasileira. v.2. São Paulo: Editora Hucitec; Editora da Universidade de São Paulo. 1991.
SOURNIA, Jean-Charles.

Histoire de la médecine. Paris: La Decouverte. 1997.

VESSURI, Hebe.

Los papeles culturales de la ciencia en los países subdesarrollados. In: Saldaña, Juan José (Ed.). El perfil de la ciencia en América. Cuadernos de Quipu, v.1, p.80-95. 1986. 